\title{
Exploring Perceptions and Practices of Biomedical Norms during Exclusive Breastfeeding among HIV-Positive Lactating Mothers in Mozambique
}

\section{Carlos Eduardo Cuinhane ${ }^{1,2 *}$, Gily Coene ${ }^{3}$, Kristien Roelens ${ }^{4}$ and Christophe Vanroelen ${ }^{5}$}

${ }^{1}$ Department of Sociology, Vrije Universiteit Brussel (Brussels University), RHEA - Research Centre Gender, Diversity and Intersectionality, Brussels, Belgium ${ }^{2}$ Department of Sociology, Eduardo Mondlane University, Maputo, Mozambique

${ }^{3}$ Vrije Universiteit Brussel (Brussels University), RHEA - Research Centre Gender, Diversity and Intersectionality, Brussels, Belgium

${ }^{4}$ Universiteit Gent (Ghent University), Ghent, Belgium

${ }^{5}$ Vrije Universiteit Brussel (Brussels University), Brussels, Belgium

\begin{abstract}
Introduction: To prevent passing infection to their infants, Mozambican mothers with HIV are advised to follow biomedical norms during breastfeeding. However, little is yet known about how HIV-positive mothers perceive biomedical norms during the breastfeeding period.
\end{abstract}

Objective: To analyse lactating mothers' perceptions and compliance with biomedical norms recommended for reducing the risk of mother-to-child transmission of HIV via breastfeeding

Method: A qualitative study was carried out consisting of in-depth interviews with 59 HIV-positive lactating mothers. This involved 5 focus group discussions, direct observation and 6 semi-structured interviews with nurses. We used Bourdieu's theory of practice as a guiding framework for data analysis.

Results: Findings revealed participants had mixed perceptions and inadequate knowledge about breast milk and exclusive breastfeeding. As well, participants struggled to comply with some biomedical norms. Approximately half of the participants breastfed immediately after childbirth. Most participants do breastfeed on demand and all participants complied with prescription regarding antiretroviral therapy for their infants. Of the 59 participants, 53 complied with prescription of antiretroviral therapy for themselves.

A total of 56 participants did not comply with exclusive breastfeeding to the sixth month. This was due to a lack of knowledge about exclusive breastfeeding, the perception that both breast milk and formula were not enough to feed the baby up to the age of six months. Other factors included returning to school or work, illness of the mother and child, lack of disclosure of HIV status of the mother as well as social norms.

Conclusion: The study results suggest participants' perceptions, incorporated learned experiences and the social environment they inhabit seem to influence compliance to biomedical norms. These norms seem new, and participants are still processing its incorporation. Health education on exclusive breastfeeding and prevention of mother-to-child HIV transmission should take into account the participant's perceptions and their social environment.

Keywords: Exclusive breastfeeding; HIV-positive lactating mother; Mozambique

\section{Introduction}

The World Health Organization [1] recommends lactating mothers living with HIV should follow biomedical norms during the breastfeeding period. This involves breastfeeding the infants within the first hour of birth, practicing exclusive breastfeeding (EBF) in the firsts six months after childbirth, and adhering to antiretroviral therapy (ART) for the lactating mother and the infant [2].

In Mozambique, like many other sub-Saharan countries, all lactating mothers are recommended to breastfeed in the first hour after childbirth. This stimulates breast milk production, breastfeeding on demand, and exclusive breastfeeding during the first six months after childbirth regardless of their HIV status [3,4].

The Mozambican Ministry of Health recommends two types of infant feeding: breast milk and formula milk. However, the use of breast milk is preferred [4]. HIV-positive lactating mothers are also advised to comply with antiretroviral therapy throughout breastfeeding for themselves and to adhere to antiretroviral therapy for their infants for the six weeks following childbirth [3].
Practicing exclusive breastfeeding implies an infant is fed on breast milk without any additional food such as solids or fluids - including water; except for drops or syrup containing vitamins and minerals or medicines prescribed by healthcare providers [1]. As for infants fed formula, it was recommended not to feed any additional food or liquids during the first six months after childbirth [4].

Benefits of exclusive breastfeeding for the infants are welldocumented $[2,5,6]$. These include nutritional benefits [2] and enhancement of the development of the brain, intestines, and immune

*Corresponding author: Carlos Eduardo Cuinhane, Vrije Universiteit Brusse (Brussels University), RHEA - Research Centre Gender, Diversity and Intersectionality, Brussels, Belgium; Tel: (+258) 824080890; Fax: (+258) 21485402 E-mail: c.cuinhane@hotmail.com

Received March 23, 2017; Accepted April 17, 2017; Published April 24, 2017

Citation: Cuinhane CE, Coene G, Roelens K, Vanroelen C (2017) Exploring Perceptions and Practices of Biomedical Norms during Exclusive Breastfeeding among HIV-Positive Lactating Mothers in Mozambique. J AIDS Clin Res 8: 687. doi: 10.4172/2155-6113.1000687

Copyright: (c) 2017 Cuinhane CE, et al. This is an open-access article distributed under the terms of the Creative Commons Attribution License, which permits unrestricted use, distribution, and reproduction in any medium, provided the original author and source are credited. 
system of the infant [7]. As well, it prevents infants from morbidity and mortality [8], diarrhoea, respiratory infection and skin infection [9].

Exclusive breastfeeding also benefits lactating mothers because it prevents breast and ovarian carcinoma, increases the duration of amenorrhoea and reduces the risk of type 2 diabetes [10]. As well, breast milk is considered cheaper than formula milk [6]. Moreover, exclusive breastfeeding strengthens the bond between the mother and the infant [7].

Among HIV-positive women, exclusive breastfeeding reduces the risk of postnatal HIV transmission [11]. However, this benefit is only possible if lactating mothers comply with antiretroviral therapy during breastfeeding [12]. Lack of compliance of exclusive breastfeeding and antiretroviral therapy may result in high risk of mother-to-child transmission of HIV (MTCT). In developing countries, it is estimated mother-to-child HIV transmission ranges between 25 to 35\% during the first six months of breastfeeding [13].

Adherence to exclusive breastfeeding implies leaving behind social and cultural norms associated with breastfeeding practices such as mixed feeding and breastfeeding cessation before infants are six months old. However, studies $[14,15]$ have documented most lactating mothers do not fully practise exclusive breastfeeding within the first six months following childbirth no matter what their HIV status.

Despite implementation of polices to promote exclusive breastfeeding $[4,16]$ and prevention of mother-to-child transmission of HIV [3] exclusive breastfeeding is still a concern in Mozambique. In 2011, the Mozambique Demographic Health Survey (DHS) estimated at the national level, exclusive breastfeeding to the age of six months only amounted to $37 \%$ regardless of the HIV status of the lactating mother [17]. Nevertheless, this average is considered slightly higher than the sub-Saharan Africa average, which was 34\% in 2010 [18].

Studies [19-21] have documented low adherence to exclusive breastfeeding and the practice of mixed feeding among lactating mothers who are unaware of their HIV status. Mother-to-child transmission of HIV through breastfeeding has also been reported [22]. However, little is known about how lactating mothers living with HIV actually behave during breastfeeding since the implementation of the aforementioned polices on exclusive breastfeeding.

Lack of exclusive breastfeeding in Sub-Saharan Africa has been associated with biological causes [7,15,23], psychological factors [24], the socioeconomic environment $[7,15,25]$, poverty [26] and a perception that baby boys are more demanding to breastfed than baby girls [23].

Studies $[27,28]$ have also reported low adherence to antiretroviral therapy during postpartum period. The most common impediments are economic, emotional stress, depression, lack of HIV disclosure and pill burden $[27,29,30]$.

These aforementioned studies have stressed structural determinants of exclusive breastfeeding and antiretroviral therapy adherence during the postpartum period. However, little is yet known about how the adherence to exclusive breastfeeding and antiretroviral therapy are influenced by behavioural factors. As well, we do not know which perceptions explain breastfeeding practices among HIV-positive mothers in Mozambique.

This qualitative study, therefore, explores perceptions and practices of exclusive breastfeeding among HIV-positive lactating mothers living in the rural province of Maputo. It analyses HIV-positive lactating mothers' compliance to biomedical norms recommended to reduce the risk of mother-to-child transmission of HIV during breastfeeding.
Infant feeding has always been conceived as a biomedical issue [31]. However, social scientists have demonstrated infant feeding is also a social and cultural practice [32]. It is considerably influenced by the social and cultural norms of the community [33].

Some authors $[33,34]$ suggest mothers breastfeed because they are socio-culturally deemed responsible for meeting all of their children's needs. Thus they strive to follow the recommended biomedical guidelines to minimise potential health risks and achieve the social status of a "good mother" [35]. While others argue that mothers breastfeed because it is their role and it is an expected practice from the family and society $[33,36]$. Nonetheless, other authors suggest breastfeeding as an oppressive practice to women [37].

In order to analyse mothers' adherence to exclusive breastfeeding and antiretroviral therapy, we use the theory of practice as underlined by Pierre Bourdieu [38]. This theory helps to understand how both structural and individual factors may influence breastfeeding practices within a specific context.

Bourdieu argues that food and eating practices depend on the ideas people have about the body and the effects of the food upon the body on its strength, health and beauty - and the categories used to evaluate these effects. In this sense, Bourdieu suggests food and eating practices are associated with gender, identity as well as one's position and status within the society [32]

Based on Bourdieu's theory, we can explain that selecting the type of infant feeding, the way of treating it, feeding practices and the duration of exclusive breastfeeding also depends on mothers' perceptions, incorporated learned experiences and their social environment.

Bourdieu's theory thus explains how HIV-positive lactating mothers perceive and practise exclusive breastfeeding and adhere to antiretroviral therapy to prevent HIV transmission to their infants. It also helps to understand the interplay of individual and structural factors influencing adherence to biomedical norms during breastfeeding in rural Mozambique. Therefore, it can contribute to a better understanding on how to improve infant health, and how to prevent practices placing infants to the risk of HIV infection.

\section{Methodology}

\section{Study design and study sites}

This qualitative study was undertaken in Namaacha and Manhiça, rural districts of Maputo province, located in the south of Mozambique. In 2015, Namaacha district had a population of 51257 [39] and operated 10 healthcare facilities. Approximately 263736 inhabitants lived in Manhiça district with 14 health facilities and one rural hospital. These investigation sites were relevant for this study because they have the highest prevalence of HIV/AIDS in the country, accounting for $26 \%$ of all pregnant women living with HIV [40].

\section{Recruitment of participants and data collection}

Recruitment and interviews of study participants took place between January and March 2015 in six health facilities implementing a program of prevention of mother-to-child transmission of HIV. Three health facilities were selected in each district. One was located at the centre of the district and two in the neighbourhood. The centre of the district is relatively urbanised, whilst the neighbourhood has more rural characteristics. These discrepancies were taken into account for analysis purposes.

Participants consisted of a purposive sample of $59 \mathrm{HIV}$-positive lactating mothers whose children were aged between zero to two 
years - 25 in Namaacha district and 34 in Manhiça district. We used a saturation method $[41,42]$ to design the study sample size. These participants were especially important in accessing mothers' perceptions and practices regarding exclusive breastfeeding and adherence to antiretroviral therapy.

To select participants, the main researcher approached all mothers during a postnatal visit to a child at risk clinic (CRC). Those who agreed to participate were interviewed. A total of 59 in-depth interviews were performed, out of which 25 with mothers whose infants were zero to six months of age and 34 mothers with infants aged seven to eighteen months. Direct observation was also used to collect data on the type of infant feeding practice used among mothers.

The study also included 5 focus group discussions (FGD) - three in Manhiça district and two in Namaacha district - all with HIV-positive women. Each FGD had between 6-10 participants.

Data collection tools were developed from the literature review on breastfeeding and adherence to antiretroviral therapy. We considered the biomedical recommendations underlined by the World Health Organization [1] as the main themes. Next, an interview guide with general themes was designed. This template enabled the introduction of more probing questions during interviews to assess narratives from the participants.

For those who could read and write Portuguese - Mozambique's national tongue - individual in-depth interviews and FGDs were conducted in this language. Rhonga, the local vernacular language, was used for those who could not understand Portuguese. Six semistructured interviews were also conducted with maternal and child health $(\mathrm{MCH})$ nurses working on prevention of mother-to-child transmission of HIV program. One nurse was interviewed in each health facility.

\section{Procedure}

This study obtained ethical clearance from the Faculty of Medicine at Eduardo Mondlane University and the Maputo Central Hospital Bioethics committee, protocol number CIBS FM\&HCM/73/2014. Verbal information about the objective of the study was provided, and written consent was presented to each participant to make an informed choice on whether or not they wanted to participate in the study.

All participants read and signed the informed consent forms. Those who could not read and write, chose someone in their trust to translate the information into the local language and to sign on their behalf. Three sociologists participated in the data collection: one male main researcher (the first author) and two female assistant researchers. These researchers were then instructed on the objectives of the study and data collection instruments. The main researcher coordinated fieldwork, interviewed the participants and moderated the FGDs.

\section{Data Analysis}

A thematic analysis approach was applied to obtain key themes emerging from the data. Beyond this, the analysis involved five stages.

First, interviews were transcribed and then translated from Portuguese to English. Second, each transcription was read more than once, and initial codes were generated. Third, these codes were applied to identify and search various themes across the data. Fourth, identified themes were revised according to the research objectives and final themes were then defined. Quantitative data emerging from interviews were summarised and presented in tables and figures.

\section{Results}

\section{Demographic characteristics of the study participants}

Table 1 summarises the demographic characteristics of the study participants. The majority were between 18 and 34 years, married or living with a partner. Most were farmers and had more than one child. Some of these participants lacked formal education.

The majority of participants were economically dependent of their partners. Nearly all were members of a Protestant church, while some were Catholic or Muslim.

All participants attended antenatal visits during pregnancy. A total of 55 participants reported to have given birth at the health facility while 4 gave birth at home. All lactating mothers attended postnatal visits. During antennal and postnatal visits, the participants had received information about how to breastfeed, how long they should exclusively breastfeed, and how to take care of their babies and also themselves.

This study comprised five key themes emerging during interviews with the participants:

1) Timing the onset of breastfeeding,

2) Perception of breast milk and exclusive breastfeeding,

3) Exclusive breastfeeding and mixed feeding practice,

4) Adherence of antiretroviral therapy, and

5) Management of illness during breastfeeding period.

These themes enabled our research team to analyse women's compliance to biomedical norms during the exclusive breastfeeding period.

\section{Timing the onset of breastfeeding after childbirth}

Figure 1 shows the onset of breastfeeding after childbirth among the participants. Approximately half of participants breastfed their babies within the first hour following giving birth. These participants were most influenced by nurses, mothers-in-law as well as their own previous experiences of breastfeeding.

However, a considerable number of participants initiated breastfeeding more than one hour after childbirth. This was primarily due to the mothers' biological health problems. These women made comments such as: "I was weak after childbirth" or "I had no milk in my breasts".

Others could not breastfeed because of the baby's biological problems, such as "The baby was born small and was under intensive care" or "the baby could not suck", or "the baby was born sick and was transferred to another hospital, and was under intensive care".

Participants also said they could not breastfeed when the babies were in intensive care, and nurses did not advise them to express breast milk manually for the babies. Some participants did not breastfeed immediately because they were advised not to by nurses. Others delayed making a decision about what the infant should be fed, while others perceived that a baby could only be breastfed after he/she started crying.

\section{Decision making on the type of infant feeding}

Most participants used breast milk to feed their babies. Nurses and mothers-in-law encouraged the participants to elect for this type of feeding. However, a considerable number of participants said they personally made the decision to breastfeed. 


\begin{tabular}{|c|c|c|c|}
\hline Characteristics of participants & Manhiça $(n=34)$ & Namaacha $(n=25)$ & Total \\
\hline \multicolumn{4}{|l|}{ Age range } \\
\hline $18-24$ & 14 & 10 & 24 \\
\hline $25-34$ & 17 & 11 & 28 \\
\hline $35-39$ & 3 & 4 & 7 \\
\hline \multicolumn{4}{|l|}{ Educational Level } \\
\hline None & 10 & 4 & 14 \\
\hline Less than primary education (1-6 years) & 8 & 6 & 14 \\
\hline Primary education completed or more ( $7-9$ years) & 15 & 12 & 27 \\
\hline Secondary education completed (12 years) & 1 & 3 & 4 \\
\hline \multicolumn{4}{|l|}{ Marital Status } \\
\hline Single & 5 & 7 & 12 \\
\hline Married/Living with a partner & 27 & 17 & 44 \\
\hline Divorced/Widow & 2 & 1 & 3 \\
\hline \multicolumn{4}{|l|}{ Number of Children } \\
\hline $1-2$ & 20 & 14 & 34 \\
\hline $3-4$ & 11 & 7 & 18 \\
\hline $5-6$ & 3 & 4 & 7 \\
\hline \multicolumn{4}{|l|}{ Occupation } \\
\hline Factor worker & 0 & 1 & 1 \\
\hline Farmer & 24 & 19 & 43 \\
\hline Housemaid & 2 & 1 & 3 \\
\hline Own business/sale & 6 & 1 & 7 \\
\hline Student & 2 & 1 & 3 \\
\hline Teacher & 0 & 2 & 2 \\
\hline
\end{tabular}

Table 1: Demographic characteristics of the study participants.

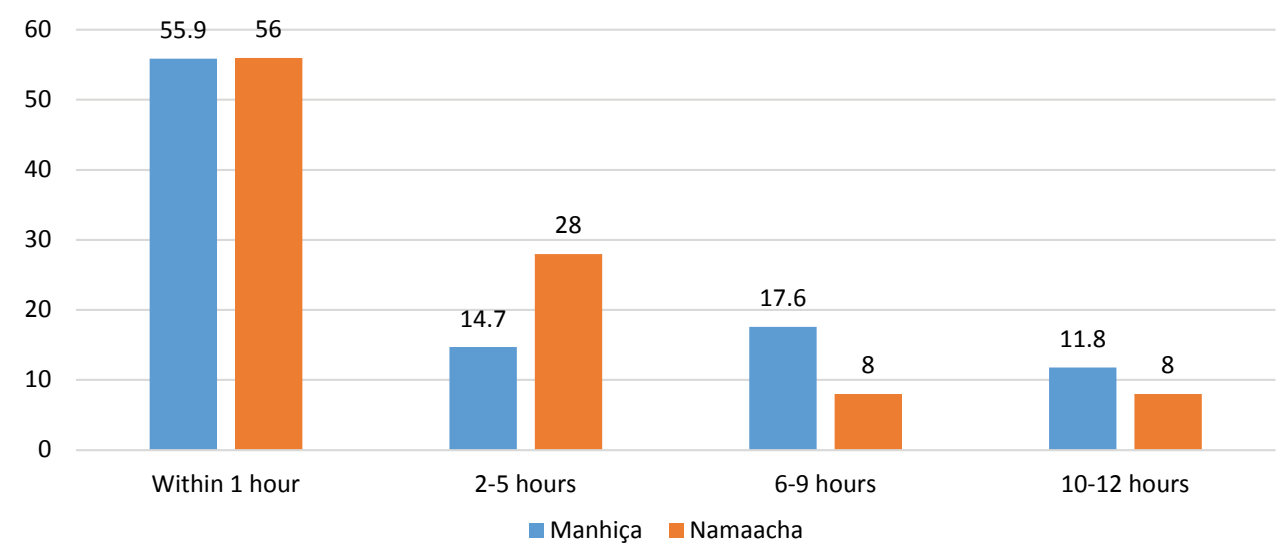

Figure 1: Onset of breastfeeding after childbirth among the participants.

Few participants who used formula actually chose this option themselves. Most were advised by nurses to use formula because of biological problems such as lack of breast milk. Other participants also chose formula because they had money to buy it during the first six months after childbirth.

Nurses said that although breast milk was preferred, they also advised women to use formula. This advice was given during antenatal care at the time of childbirth to women who were working, studying or could not immediately produce breast milk.

\section{Perceptions of breast milk and exclusive breastfeeding}

Perceptions of breast milk: Participants had mixed perceptions. For some, breast milk was viewed as good and healthy for the baby. Breast milk is considered a natural food source and very accessible. Moreover, it enabled the babies to grow quickly and develop strong bones.
For others, breast milk was viewed as the cheapest source of infant feeding. It was considered cost-free compared to infant formula. Some participants also recognised breast milk as a protector against diseases, such as diarrhoea and HIV.

One participant said: "Breast milk is good because it protects babies against disease such as diarrhoea. It also prevents the transmission of HIV from the mother to the baby." (Mother of a child aged 12 months).

However, some participants regarded breast milk as a cause of diarrhoea. Some reported their babies experiencing diarrhoea when fed breast milk. Others believed breast milk could pass on HIV from the mother to the baby. They said they only used breast milk to feed their babies because they had no money to buy formula. In their view, formula prevents the transmission of HIV from mothers to their babies. 
Perceptions of exclusive breastfeeding: Most participants perceived exclusive breastfeeding as a means for their babies to grow up healthy. Some participants, exclusive breastfeeding meant feeding the baby via "traditional feeding that is from the mother". For others, exclusive breastfeeding meant they still had the opportunity to feed their babies because they did not know an HIV-positive mother could breastfeed her baby. These participants wanted to breastfeed more than six months - the limited period recommended by the nurses.

Some participants perceived exclusive breastfeeding as a responsibility. Practicing exclusive breastfeeding meant that one was an adult and held the responsibility to feed and take care of the baby. Exclusive breastfeeding was also viewed as a way to strengthen the relationship between the baby and the mother. They said exclusive breastfeeding enabled a woman to show everybody that she was the mother because the baby sucked her breasts.

Yet, a considerable number of participants perceived exclusive breastfeeding as not enough to properly feed a baby up to six months of age. This perception was common for both mothers using breast milk and formula. These participants viewed breast milk or formula alone as light food. Therefore, they believed the baby would not be satisfied after the age of three months. One of the lactating mothers said:

I exclusively breastfed my baby up to [the age of] three months because the baby could still get satisfied. But after three months, I started giving porridge to the baby because I think he may not be satisfied only with breast milk. When I give him only breast milk he cries. So, after giving him breast milk, I prepare porridge for him to ensure that he is satisfied. (Mother of a child aged 4 months).

Other participants said exclusive breastfeeding could delay the baby in starting to walk. They perceived some mothers have "good" breast milk, while others have "bad" breast milk. Participants explained when a mother has "good" breast milk her baby grows up strong and quickly, and gains the proper amount of weight. But, when a mother has "bad" breast milk, her baby does not grow quickly and will lose weight.

A few participants considered exclusive breastfeeding to be beneficial to them, but did not explain how it contributed to their health.

\section{Exclusive breastfeeding and mixed feeding practice}

Table 2 summarises the practice of exclusive breastfeeding (EFB) and mixed feeding (MF) among the participants during the first six months following childbirth. Exclusive breastfeeding among HIVpositive mothers was rare in both study settings. Both mothers using breast milk and formula practised mixed feeding. They introduced water and traditional remedies as early as the first week after birth, regardless of their age, level of education, marital status, number of children or occupation.

At the time of the study, a few mothers practised exclusive breastfeeding, with babies between the ages of five days and two months. Mothers with babies between the ages of 7 and 18 months revealed they rarely practice exclusive breastfeeding in the first six months after giving birth.

\section{Reasons for practicing exclusive breastfeeding}

Participants stated they practiced exclusive breastfeeding because they believed it was good for the baby. It enabled the baby to be strong and healthy and to grow faster. They also said the nurses motivated them to practice exclusive breastfeeding.

Some participants used exclusive breastfeeding by choice while others did so due to lack of availability of any other kind of infant

\begin{tabular}{|c|c|c|c|c|}
\hline \multirow{3}{*}{ Characteristics of participants } & \multirow{2}{*}{\multicolumn{2}{|c|}{$\begin{array}{l}\text { Manhiça }(n=34) \\
\text { How do you breastfeed your baby? }\end{array}$}} & \multirow{2}{*}{\multicolumn{2}{|c|}{$\begin{array}{c}\text { Namaacha }(n=25) \\
\text { How do you breastfeed your baby? }\end{array}$}} \\
\hline & & & & \\
\hline & EBF & MF & EBF & MF \\
\hline \multicolumn{5}{|l|}{ Age range } \\
\hline 18-24 & 2 & 12 & 1 & 9 \\
\hline $25-34$ & 1 & 16 & 1 & 10 \\
\hline $35-39$ & 0 & 3 & 0 & 4 \\
\hline \multicolumn{5}{|l|}{ Educational Level } \\
\hline None & 1 & 9 & 1 & 3 \\
\hline Less than primary education (1-6 years) & 2 & 6 & 1 & 5 \\
\hline Primary education completed or more (7-9 years) & 0 & 15 & 0 & 12 \\
\hline Secondary education completed (12 years) & 0 & 1 & 0 & 3 \\
\hline \multicolumn{5}{|l|}{ Marital Status } \\
\hline Single & 1 & 4 & 1 & 6 \\
\hline Married/Living with a partner & 1 & 26 & 1 & 16 \\
\hline Divorced/Widow & 1 & 1 & 0 & 1 \\
\hline \multicolumn{5}{|l|}{ Number of Children } \\
\hline $1-2$ & 2 & 18 & 1 & 13 \\
\hline $3-4$ & 1 & 10 & 1 & 6 \\
\hline $5-6$ & 0 & 3 & 0 & 4 \\
\hline \multicolumn{5}{|l|}{ Occupation } \\
\hline Factory worker & 0 & 0 & 0 & 1 \\
\hline Farmer & 3 & 21 & 2 & 17 \\
\hline Housemaid & 0 & 2 & 0 & 1 \\
\hline Own business/sale & 0 & 6 & 0 & 1 \\
\hline Student & 0 & 2 & 0 & 1 \\
\hline Teacher & 0 & 0 & 0 & 2 \\
\hline
\end{tabular}

Table 2: Practice of exclusive breastfeeding (EBF) and mixed feeding (MF) among the participants in the first six months after childbirth. 
nourishment. Still others said their babies were still too young (1-2 months) and did not accept any other types of food. In some communities the use of breast milk was considered a norm. One participant explained it in the following way:

I breastfed my baby with breast milk up to six months because I learnt about breastfeeding in my village. I learnt that when a baby is fed with breast milk, he grows up very well and he does not suffer from stomach-ache. I come from a village where everybody uses only breast milk to feed the babies. Nobody uses other type of milk to feed the baby. (Mother of a 9 months old child).

Participants also said they practiced exclusive breastfeeding because of a lack of money to buy formula. They perceived formula as appropriate for babies because it reduced risk of transmission of HIV during the breastfeeding period. However, others believed breast milk could prevent passing HIV from mother to the infant.

Participants who practiced exclusive breastfeeding did not give other liquids or solid food to their babies. They said they were fearful water or traditional remedies could harm the baby. They also confirmed the nurses had advised them not to give other liquids or solid food until the baby was a full 6 months old.

Other participants said they had not yet fed their babies any liquids other than breast milk because they were still young to eat anything else. However, one participant said she had previously given other liquids to her babies once they were one month old.

I have not yet given water to my baby because he is still young. In my previous children, I gave water to my first born when he was one month. (Mother of a 5 day old child).

\section{Type of mixed feeding}

Participants practiced two types of mixed feeding:

1) Introduction of liquids such as formula, water, traditional remedies, and Gripe water - a liquid used to relive infantile colic and gastrointestinal troubles in the infants [43]; and

2) The introduction of solid food.

Participants gave water, traditional remedies and gripe water to the baby regardless their place of residence, age, marital status, level of education, occupation, or the number of children they had. This practice was common to both lactating mothers and those who chose formula to feed their babies. Babies were given liquids as early as one day to one week after birth.

Solid food was introduced as early as two months. This type of mixed feeding comprised breast milk and porridge, infant formula and porridge, breast milk and food and sometimes combined breast milk, formula and porridge.

The decision for giving water and traditional remedies to the baby was mostly informed by the family, the couple - both wife and husband - and their friends. Conversely, Gripe water was recommended by nurses and family members.

\section{Reasons for practicing mixed feeding}

Participants presented various reasons for practicing mixed feeding. Mothers who were using breast milk introduced formula when they perceived the baby was not satisfied with just breast milk. Others started using formula due to the lack of enough breast milk and yet others, stopped breastfeeding when they returned to work and school.
Some participants chose to use formula to feed the baby, but the nurses advised them to give colostrum to the baby in the first day after childbirth. These participants started with breast milk and then switched to formula.

However, other participants were forced to abandon exclusive breastfeeding before the baby was six months old, when they disclosed their HIV-positive status to their husbands. One participant explained that she followed the nurses' recommendations, but she had to stop breastfeeding when her husband learned she was HIV-positive. She added that her husband decided to feed the baby with formula.

I used breast milk to feed the baby up to 2 months. Health providers recommended me to use breast milk up to 6 months. But my husband forced me to interrupt when he discovered that I was HIV-positive. From there and on, he decided to buy and use formula to feed the baby. (Mother of a 15 months old child).

Participants gave water to the baby to quench thirst, but also to treat diseases such as diarrhoea and hiccups. Grip water was also given to the baby to prevent or treat complaints like stomach-ache. Sometimes, grip water was used as a substitute for traditional remedies. In most cases, use of grip water was not prescribed by the nurses.

Traditional remedies were also administered to babies soon after childbirth. Participants explained these remedies combated worms and epilepsy. Many of these women believe babies are born with these diseases. Additionally, they erroneously believed these ailments were not treated at the health facility and only by the traditional medicines. Most participants reported traditional remedies were part of their social norm and they had to obey the advice of their husbands or other family members.

Nurses said that always recommend mothers not to give new-borns any liquid such as water, traditional remedies, or tea. This should only be done after the age of six months. However, they recognised the fact mothers always gave water and traditional remedies to their babies because it was part of their social norm. They also stated new mothers were most often forced into doing so by family members, especially mothers and grandmothers.

Both participants using breast milk and formula reported introducing porridge or other more solid food because they believed the baby was not satisfied with only breast milk or formula. They said after breastfeeding, the baby would still cry and that meant he/she was still hungry.

Others introduced porridge early as a way to prepare for exclusive breastfeeding cessation. They also perceived early introduction of porridge could prevent illness which could possibly rise due to abrupt breastfeeding cessation. One lactating mother put it this way:

I use formula and porridge to feed the baby because the nurses recommended me. I was recommended to stop breastfeeding when the baby completes 6 months. So, as the baby is 4 months now, I have started to feed him on formula and porridge so that he can be used to it. This will avoid problems such as rejecting formula and porridge or other illnesses that can arise when I abruptly stop breastfeeding at 6 months. (Mother of a child, age 4 months).

Some participants preferred to feed their babies breast milk, formula and porridge to enhance diet. They believed their babies should have a varied diet to grow well, and therefore, they should not eat the same food every day. One participant explained her views as follows: 
I feed the baby with breast milk, formula and porridge because the baby must vary the type of food. It is an option because I think the baby cannot eat only one type of food, because otherwise he will not grow up very well. (Mother of a 5 months old child).

Most participants regarded mixed feeding as beneficial for the baby because it enhanced growth. In a FGD, lactating mothers said they practiced mixed feeding because breast milk alone was not enough to nourish the baby and strengthen its body all the way up to six months of age. They also disclosed the nurses got angry with them if the baby was not growing well and didn't have "good weight". These mothers were predominantly concerned about the "good weight" of their babies to avoid reprimands from the nurses.

However, other participants introduced solid food due to food shortage. Some participants said they lacked food for themselves and this negatively influenced production of breast milk. Several said they decided to feed porridge to the baby to prevent malnutrition or death before the age of six months.

During data collection, we observed lactating mothers feeding their 4 months old babies with solid food such as biscuits in the health facility and during community focus group discussions. These mothers said their babies were hungry and they could not breastfeed because they did not have enough breast milk to properly feed their babies.

Some participants in FGD reported that exclusive breastfeeding up to six months was a new practice recommended by the nurses. In their past experiences exclusive breastfeeding lasted four months. During this period, they also gave water and traditional remedies to the babies.

Participants said practising exclusive breastfeeding up to six months was a challenge because most of them had to return to work between 3 to 4 months after childbirth. Farming days lasted between 4 and 6 hours, and during that time, they left their babies at home. Several said nurses did not advise them to express breast milk, to keep it in a safe place or have the child minder give it to the baby when they were absent.

They also stated their reservations about expressing breast milk. In their communities, people did not think it was advisable because babies need to be fed warm breast milk - which is only possible when it is sucked directly from the mother. As well, they believed there was no guarantee saved breast milk would remain fresh due to lack of available cooling as well as the lack of adults present to control it. Moreover, some participants feared expressed breast milk could be harmed or bewitched by "bad" people.

\section{Timing everyday exclusive breastfeeding practice}

Most participants with babies between the ages of zero to six months reported breastfeeding many times per day or whenever the baby wanted it. Nevertheless, a considerable number of participants said they only breastfed whenever their baby cried. Participants also said breastfeeding on demand was common during the first two or three months after childbirth, and before the introduction of solid food.

Some participant's breastfed many times per day because they supposed their babies liked to suck and breast milk was the only recommended food during the first six months. Conversely, other participants believed when the baby cried, it meant he/she was hungry.

Others said their babies took a long time sucking and they perceived this to mean the child could pass considerable time without feeling hungry. Moreover, some participants said they could not produce enough breast milk to feed the baby every time he/she cried due to their own biological problems.

\section{Knowledge of duration of exclusive breastfeeding}

The duration of exclusive breastfeeding varied according to the knowledge of the mothers. Table 3 summarises the knowledge of duration of exclusive breastfeeding. Most participants had no clear understanding of the reasons for or the duration of exclusive breastfeeding. Some said exclusive breastfeeding lasted between 3 and 5 months while others knew exclusive breastfeeding lasted 6 months, and while few had the notion exclusive breastfeeding lasted more than 6 months.

Participants exclusively breastfed their babies up to three months because they presumed the baby's stomach was still weak and could not support any food other than breast milk or formula.

Some participants were of the opinion exclusive breastfeeding should last six months because during this period, the baby was young and still developing and should be fed only breast milk. They added their babies should not eat other types of food because it could cause stomach-aches.

\section{Adherence to antiretroviral therapy during breastfeeding}

All participants said that their babies received antiretroviral syrup after childbirth. They also received oral Nevirapine - an antiretroviral for the baby - to be given at home over the course of six weeks.

Figure 2 illustrates adherence to antiretroviral therapy among lactating mothers during breastfeeding. The majority of participants took antiretroviral drugs during the breastfeeding period. Most participants reported taking antiretroviral drugs to prevent passing on HIV to the baby. Others continued with antiretroviral therapy beyond the breastfeeding interval and planned to do so for the remainder of their lives.

The major challenge to compliance with prescribed antiretroviral therapy was the lack of food. Participants reported facing hunger because both breastfeeding and antiretroviral drugs required proper nutrition. They divulged they faced food shortages due to draught and lack of money.

The nurses confirmed most mothers complied with instructions regarding antiretroviral therapy because they were afraid their babies could be infected during the breastfeeding period. Nonetheless, they also said there were still some risks among mothers who did not disclose their HIV-positive status to their husbands. Some of these mothers adhered to antiretroviral therapy for the baby and themselves without informing their husbands. However, once their husbands discovered this, these women were often forced to stop treatment of prevention of mother-to-child transmission of HIV. One nurse disclosed the following:

Last year (2014), we had a problem here in the health facility. Our colleague almost suffered aggression because a patient's husband discovered that his wife and the baby were receiving HIV treatment. He said that he did not want treatment of prevention of mother-to-child transmission of HIV because none of his family members was suffering from AIDS. He ordered the nurses to stop the treatment. He added that if they insisted with treatment he would take his wife and the baby to another health facility. The mother and the child interrupted antiretroviral therapy; and we have never heard about them [since] (Nurse). 


\begin{tabular}{|c|c|c|c|c|c|c|}
\hline \multirow{3}{*}{ Characteristics of participants } & \multicolumn{3}{|c|}{ Manhiça $(n=34)$} & \multicolumn{3}{|c|}{ Namaacha $(n=25)$} \\
\hline & \multicolumn{3}{|c|}{ Duration of EBF } & \multicolumn{3}{|c|}{ Duration of EBF } \\
\hline & 3-5 months & 6 months & More than 6 months & 3-5 months & 6 months & More than 6 months \\
\hline \multicolumn{7}{|l|}{ Age range } \\
\hline $18-24$ & 4 & 7 & 3 & 4 & 4 & 2 \\
\hline $25-34$ & 1 & 11 & 5 & 3 & 7 & 1 \\
\hline $35-39$ & 0 & 2 & 1 & 2 & 2 & 0 \\
\hline \multicolumn{7}{|l|}{ Educational Level } \\
\hline None & 1 & 6 & 1 & 2 & 2 & 1 \\
\hline Less than primary education (1-6 years) & 2 & 2 & 4 & 3 & 2 & 1 \\
\hline $\begin{array}{l}\text { Primary education completed or more (7-9 } \\
\text { years) }\end{array}$ & 0 & 11 & 4 & 2 & 8 & 2 \\
\hline Secondary education completed (12 years) & 0 & 1 & 0 & 2 & 1 & 0 \\
\hline \multicolumn{7}{|l|}{ Marital Status } \\
\hline Single & 2 & 3 & 0 & 3 & 4 & 0 \\
\hline Married/Living with a partner & 2 & 16 & 9 & 6 & 8 & 3 \\
\hline Divorced/Widow & 1 & 1 & 0 & 0 & 1 & 0 \\
\hline \multicolumn{7}{|l|}{ Number of Children } \\
\hline $1-2$ & 4 & 12 & 4 & 4 & 9 & 1 \\
\hline $3-4$ & 0 & 7 & 4 & 4 & 3 & 0 \\
\hline $5-6$ & 1 & 1 & 1 & 1 & 1 & 2 \\
\hline \multicolumn{7}{|l|}{ Occupation } \\
\hline Factory worker & 0 & 0 & 0 & 0 & 1 & 0 \\
\hline Farmer & 5 & 13 & 6 & 7 & 10 & 2 \\
\hline Housemaid & 0 & 2 & 0 & 1 & 0 & 0 \\
\hline Own business/sale & 0 & 3 & 3 & 0 & 0 & 1 \\
\hline Student & 0 & 2 & 0 & 0 & 1 & 0 \\
\hline Teacher & 0 & 0 & 0 & 1 & 1 & 0 \\
\hline
\end{tabular}

Table 3: Knowledge of duration of exclusive breastfeeding (EBF) among the participants.

120

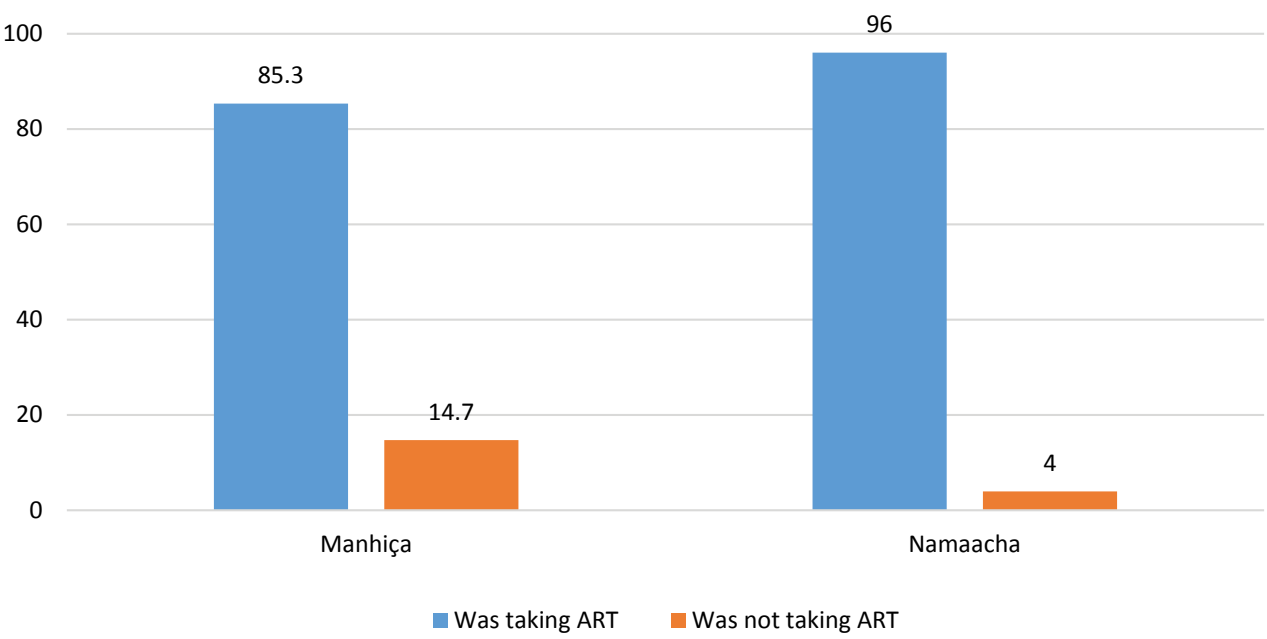

Figure 2: Adherence to antiretrovial therapy (ART) during exclusive breastfeeding among the participants.

\section{Management of illness during breastfeeding}

A considerable number of participants reported illness episodes during the breastfeeding period. The most common maladies were malaria, headache, fever, grippe and injures of the nipples. Some participants sought a health facility to treat their illnesses but few went to a pharmacy to buy medications to treat fever, constipation or headache.
Participants said they continued breastfeeding while experiencing illness episodes such as fever, constipation, grippe and malaria. However, some participants who had damage to their nipples stopped breastfeeding until they were treated even though their babies were between one week and three months old. The babies instead were fed water, formula or porridge. Only a few participants reported continuing breastfeeding because just one nipple was injured. 
Illness episodes were also experienced among participants' infants. The most reported illnesses were malaria, constipation, fever, diarrhoea and inflammation of the mouth. Most participants sought treatment for their babies at health facilities. However, some participants treated fever and constipation at home by using a homemade syrup remedy.

Some participants said their husbands, mothers and mother-inlaws decided on the treatment to be used when they or their babies experienced illness. Less commonly, some women personally made the decision on how to treat these illnesses. Nevertheless, those who used homemade syrup to treat their babies said they had been advised to do so by the nurses.

\section{Discussion}

Findings of this study revealed participants strived to comply with biomedical norms during the exclusive breastfeeding period but they faced various constraints. Most participants complied with the onset of breastfeeding, as recommended by WHO [2]. However, biological problems of the mother and baby, lack of decision-making on the type of infant feeding, and the perception that the baby should only be breastfed when he/she starts crying hampered the immediate initiation of breastfeeding as documented in other sub-Saharan countries [44-46].

This study also revealed lactating mothers had mixed perceptions and inadequate knowledge about breast milk and exclusive breastfeeding. Some participants perceived breast milk as safe while others viewed it as a risk for transmitting HIV to the baby. This conflict of belief had already been documented in earlier studies conducted in Zambia [47]. This is generally linked to inadequate health education about the benefits of exclusive breastfeeding in the presence of HIV.

These perceptions and lack of knowledge about exclusive breastfeeding tend to influence the lack of adherence to exclusive breastfeeding. Other barriers include the participants' experience of breastfeeding; the perception both breast milk and formula were not nutritious enough to feed the baby to six months of age. Similar results were documented in Mozambique [20,21] and other African countries [48-51]. Moreover, participants struggled to maintain the expected physical growth and ideal weight of their babies to avoid reprimands from the nurses rather than preventing malnutrition.

Participants did not often comply with exclusive breastfeeding due to factors such as limited maternal leave, and returning to school or farming. As well, some mothers did not disclose their HIV status or that of the baby. Often, these women were influenced by social norms, such as feeding water and traditional remedies to their babies. Also, there is inadequate counselling available to inform mothers about the advantages and duration of exclusive breastfeeding as well as its effect in the prevention of HIV. These results are congruent with other studies conducted in sub-Saharan Africa [45,52]

The socioeconomic circumstances of the participants also challenged exclusive breastfeeding and adherence to antiretroviral therapy. This study's findings revealed most participants were not able to produce an adequate milk supply. And, it was an enormous challenge to continue with antiretroviral therapy because they lacked enough food for themselves.

Despite this challenge, participants complied with antiretroviral therapy for their children as well as for themselves. This result is consistent with other studies done in sub-Saharan Africa [53,54]. However, some participants did not seek health facility treatment for their own illness episodes or those of their babies.
This study suggests that despite the role of nurses in promoting exclusive breastfeeding, there are many missed opportunities. For example, they should be advising women to express breast milk manually. This practice stimulates the production of breast milk and prolongs the lactation period. In addition, the availability of expressed breast milk is advantageous should the mother fall ill. These practices could assist mothers to exclusively breastfeed for a longer period and prevent mixed feeding.

\section{Limitation}

This study is limited to the study settings and methods used to select the participants. The research was held in two districts. It accessed only some participants who attended postnatal care at child at risk clinics (CRC). All other HIV-positive mothers who did not attend CRC were not included.

The study sample size was very limited for understanding how and why participants perceived biomedical norms in their everyday lives. It did not take in consideration the representatives of the study population. Although the sample size generated some quantitative data, it does not capture the correlation of participants' practices. Thus, the results of this study should be interpreted prudently. To minimise these limitations, we triangulated the assorted data collected with various tools in the data analysis.

\section{Conclusion}

The findings of this study have revealed participants complied with some biomedical recommendations to prevent mother-tochild transmission of HIV. This included the onset of breastfeeding after childbirth, breastfeeding on demand, as well as adherence and compliance of antiretroviral therapy for both mother and the baby.

However, the majority of participants did not comply with exclusive breastfeeding practice up to the age of six months. This was most often due to biological, social and economic factors as well as inadequate counselling on the effects of exclusive breastfeeding on the baby and HIV prevention. Also, there were mixed perceptions among the participants about breast milk and exclusive breastfeeding. And finally, there was inadequate knowledge available about exclusive breastfeeding and its relationship with prevention of mother-to-child transmission of HIV.

These findings suggest the choice of infant feeding, the manner of treating it, caring for it, feeding practices and the length of exclusive breastfeeding seem to be influenced by the participants' perceptions, incorporated learned experiences and the social environment in which they live. Therefore, the biomedical recommendations on breastfeeding appear to be a new practice which is still in the process of incorporation among lactating HIV-positive mothers.

The study proposes there is a definite need for adequate health education concerning exclusive breastfeeding practice and its relationship with mother-to-child transmission of HIV. Such education should take into account mothers' perceptions, their experiences and the environment they inhabit.

\section{Acknowledgement}

This study was funded by a project grant from the DESAFIO, Development Program in Reproductive Health; HIVIAIDS and Family Matters - a partnership project between Eduardo Mondlane University, Mozambique and Flemish Interuniversity Council (VLIR). 


\section{References}

1. WHO (2014) WHO recommendations on postnatal care of the mother and newborn 2013. WHO, Geneva.

2. WHO (2011) Exclusive breastfeeding for six months best for babies everywhere WHO library, Geneva.

3. MISAU (2011) Plano Nacional de eliminação da transmissão vertical do HIV (2012-2015). MISAU, Maputo.

\section{MISAU (2013) Política Nacional de alimentação infantile. MISAU, Maputo.}

5. Jones G, Steketee RW, Black RE, Bhutta ZA, Morris SS (2003) The bellegio child survival study group. How many child deaths can we prevent this year? Lancet 262: 65-71.

6. Giugliani ERJ (2004) Common problems during lactation and their management. J Pediatr Rio J 80: S147-S154.

7. Godfrey JR, Lawrence RA (2010) Towards optimal health: The maternal benefits of breastfeeding. J Womens Health (Larchmt) 19: 1597-1602.

8. Victora CG, Vaughan JP, Lombardi C, Fuchs SM, Gigante LP, et al. (1987) Evidence for protection by breast-feeding against infant deaths from infection diseases in Brazil. Lancet 2: 319-321.

9. Brown KH, Black RE, de Romana GL, Kanashiro HC (1987) Infant feeding practices and their relationship with diarrhoeal and other diseases in Huascar (Lima), Peru. Pediatrics 83: 31-40.

10. Chowdhary R, Sinha B, Sankar MJ, Taneja S, Bhandari N (2015) Breastfeeding and maternal health: A systematic review and met-analysis. Acta pediatrica.

11. Illif PJ, Piwoz EG, Tavengwa NV, Zunguza CD, Marinda ED, et al. (2005) Early exclusive breastfeeding reduces the risk of postnatal HIV-1 transmission and increases HIV-three survival. AIDS 19: 699-708.

12. Mofenson LM (2010) Antiretroviral drugs to prevent breastfeeding HIV transmission. Antiviral Therapy 15: 537-553.

13. de Cock KM, Fowler MG, Mercier E, de Vincenzi I, Saba J, et al. (2000) Prevention of mother-to-child HIV transmission in poor resource countries. JAMA 283: 1174-1182.

14. Lauer J, Betrán AP, Victora CG, Onís M, Barros AJD (2004) Breastfeeding patterns and exposure to suboptimal breastfeeding among children in developing countries: Review and analysis of nationally representative surveys. BMC Med 2: 26

15. Agunbiade OM, Ogunleye OV (2012) Constrains to exclusive breastfeeding practice among breastfeeding mothers in southwest Nigeria: Implication for scaling up. Int Breastfeed J 7: 1-10.

16. MISAU (2010) Multisectoral action plan for the reduction of chronic malnutrition in Mozambique. 2011-2015(2020). MISAU, Maputo.

17. INE, MISAU (2013) Inquérito Demográfico e de Saúde 2011. MISAU, Maputo.

18. WHO (2015) Health in 2015 from MDGs, millennium development goals to SDGs, sustainable development goals. WHO library, Geneva.

19. Lunet N, Barros H (2003) Use of water by breastfed children in Maputo, Mozambique. J Trop Pediatr 49: 193.

20. Agadjanian V, Hayford SR (2009) PMTCT, HAART and childbearing in Mozambique: An institutional perspective. AIDS Behav 13: S103-S112.

21. Arts M, Geelhoed D, De Schacht C, Prosser W, Alons C et al. (2011) Knowledge, beliefs, and practices regarding exclusive breastfeeding of infants younger than 6 months in Mozambique: A qualitative study. J Hum Lact 27: 25-32.

22. Micek MA, Dross N, Blanco AJ, Back IA, Matunha L, et al. (2014) Breast milk transmission of nevirapine-resistant HIV-1 to infants after single-dose nevirapina in Beira, Mozambique. J Infect Dis 210: 641-645.

23. Kimani-Murage EW, Maldise NJ, Fotso J, Kyobutungi C, Mutua M, et al. (2011) Patterns and determinants of breastfeeding and complementary feedings practices in urban informal settlements, Nairobi, Kenya. BMC Public Health 11: 396.

24. Adeyinka T, Ajibola F, Oyesoji A, Adedeji T (2008) A hospital-based assessment of breast-feeding behaviour and practices among nursing mothers in Nigeria and Ghana. Pakistan Journal of Nutrition 7: 165-171.

25. Thulier D, Mercer J (2009) Variables associated with breastfeeding duration. J Obstet Gynecol Neonatal Nurs 38: 259-268.
26. Ogbo FA, Agho KE, Page A (2015) Determinants of suboptimum breastfeeding practices in Nigeria: Evidences from the 2008 demographic and health survey. BMC Public Health 15: 259

27. Nachega JB, Uthman OA, Anderson J, Peltzer K, Wampold S, et al. (2012) Adherence to antiretroviral therapy during and after pregnancy in low-income middle-income and high-income countries: A systematic review and metaanalysis. AIDS 26: 2030-2052.

28. Phillips T, Thebus E, Bekker L, Mcintyre J, Abrams EJ, et al. (2014) Disengagement of HIV-positive pregnant and postpartum women from antiretroviral therapy services: A cohort study. J Int AIDS Soc 17: 1-10.

29. Haas AD, Msukwa M, Egger M, Tenthani L, Thweya $\mathrm{H}$ at al. (2016) Adherence to antiretroviral therapy during and after pregnancy: Cohort study on women receiving care in Malawi's Option B+ program. Clin Infect Dis 63: 1227-1237.

30. Kim MH, Zhou A, Mazenga A, Ahmed S, Markham C, et al. (2016) Why did stop? Barriers and facilitators to uptake and adherence to ART in Option B+ HIV care in Lilongwe, Malawi. PloS ONE 11: e0149527.

31. Amir LH (2011) Social theory and infant feeding. Int Breastfeed J 6: 1-3

32. Bourdieu P (1984) Distinction: A social critique of the judgement of test Massachusetts, Harvard University Press.

33. Afflerback S, Carter SK, Anthony AK, Grauerholz L (2013) Infant feeding in the age of intensive mothering and risk society. Journal of consumer culture $0: 1-19$

34. Warin N, Turner K, Moore V, Davies M (2008) Bodies, mothers and identities: Rethinking obesity and BMI. Sociol Health IIIn 30: 97-111.

35. Murphy E (1999) "Breast is best": Infant feeding decisions and maternal deviance. Sociol Health IIIn 21: 187-208.

36. Esterik PV (1994) Breastfeeding and feminism. Int J Gynecol Obstet 47: S41-S54.

37. McCarter-Spaulding D (2008) Is breastfeeding fair? Tension in feminism perspectives on breastfeeding and the family. J Hum Lact 24: 206-212.

38. Bourdieu P (1987) Outline of a theory of practice ( $3^{\text {rd }}$ Edn) Cambridge University Press, USA.

39. INE (2010) Projeções anunais da população total, urbana e rural dos distritos da província de Maputo 2007-2040. Instituto Nacional de Estatística, Maputo.

40. INS, INE, ICF (2010) Inquérito Nacional de Prevalência, Riscos comportamentais e Informação sobre o HIV e SIDA em Moçambique 2009. MISAU, Maputo.

41. Bowen GA (2008) Naturalistic Inquiry and the Saturation concept: A research note. Qual Res 8: 137-152.

42. Francis JJ, Johnston M, Robertson C, Glidewell L, Entwistle V, et al. (2009) What is an adequate sample size? Operationalising data saturation for theorybased interview studies. Psychol Health 25: 1229-1245.

43. Blumenthal I (2000) The Gripe water story. J R Soc Med 93: 172-174.

44. Edmond KM, Zandoh C, Quigley MA, Amenga-Etego S, Owusu-Agyei S, et al. (2016) Delayed breastfeeding initiation increases risks of neonatal mortality. Pediatrics 117: e380-e386.

45. Debes AK, Kohli A, Walker N, Edmond K, Mullany LC (2013) Time to initiation of breastfeeding and neonatal mortality and morbidity: A systematic review. BMC Public Health 13: S19.

46. Bekere A, Garoma W, and Beyene F (2014) Exclusive breastfeeding practices of HIV positive mothers and its determinants in selected health institutions of West Oromia, Ethiopia. J Nutr Food Sci 4: 1-8.

47. Hazemba AN, Ncama BP Sithole SL (2016) Promotion of exclusive breastfeeding among HIV-positive mothers: An explorative qualitative study. Int Breastfeed J 11.

48. Moore ER, Bergman N, Anderson GC and Medley E (2016) Early skin-to-skin for mothers and their health new-born infants (review). Cochrane Database Syst Rev.

49. Jaafar SH, Ho JJ, Lee KS (2016) Rooming-in for new mother and infant versus separate care increases the duration of breastfeeding. Cochrane Database Syst Rev. 
Citation: Cuinhane CE, Coene G, Roelens K, Vanroelen C (2017) Exploring Perceptions and Practices of Biomedical Norms during Exclusive Breastfeeding among HIV-Positive Lactating Mothers in Mozambique. J AIDS Clin Res 8: 687. doi: 10.4172/2155-6113.1000687

Page 11 of 11

50. Bosire R, Betz B, Aluisio A, Hughes JP, Nduati R, et al. (2016) High rates of Exclusive breastfeeding in both arms of peer counselling study promoting EBF among HIV-infected Kenyan women. Breastfeed Med 11: 56-63.

51. Okanda JO, Borkowf CB, Gird S, Thomas TK, Lecher SL (2014) Exclusive breastfeeding among women taking HAART for PMTCT of HIV-1 in Kisumu breastfeeding study. BMC Pediatrics 14: 280.

52. Al-Mujtaba M, Sam-Agudu NA, Khatri R (2016) Barriers to practice exclusive breastfeeding among HIV positive mothers in sub-Saharan Africa: A scoping review of counselling, socioeconomic and cultural factors. J AIDS HIV Res 8 : 70-79.

53. Psaros C, Remmert JE, Bangsbert DR, Sfren SA, Smith JA (2015) Adherence to HIV care after pregnancy and women in sub-Saharan Africa: failing of the cliff of the treatment cascade. Curr HIVIAIDS Rep 12: 1-5.

54. Ngarina M, Tarimo EAM, Naburi H, Kilewo C, Mwanyika-Sando M, et al. (2014) Women's preferences regarding infant or maternal antiretroviral prophylaxis for prevention of mother-to-child transmission of HIV during breastfeeding and their views on Option B+ in Dar es Salaan, Tanzania. PLoS ONE 9: e85310. 